\title{
Fast Delayed Rectifier Potassium Current: Critical for Input and Output of the Circadian System
}

\author{
Takashi Kudo, ${ }^{1 \star}$ Dawn H. Loh, ${ }^{1 \star}$ Dika Kuljis, ${ }^{1}$ Cara Constance, ${ }^{2}$ and Christopher S. Colwell ${ }^{1}$ \\ ${ }^{1}$ Department of Psychiatry and Biobehavioral Sciences, University of California, Los Angeles, Los Angeles, California 90024, and ${ }^{2}$ Department of Biology, \\ Hiram College, Hiram, Ohio 44234
}

The ability to generate intrinsic circadian rhythms in electrical activity appears to be a key property of central pacemaker neurons and one essential to the function of the circadian timing system. Previous work has demonstrated that suprachiasmatic nucleus (SCN) neurons express the fast delayed rectifier (FDR) potassium current and raise questions about the function of this current. Here, we report that mice lacking both Kcnc1 and Kcnc2 genes [double knock-out (dKO)] fail to express the Kv3.1 and 3.2 channels in the SCN as well as exhibit a greatly reduced FDR current. SCN neurons from these dKO mice exhibit reduced spontaneous activity during the day as well as reduced NMDA-evoked excitatory responses during the night. Interestingly, the daily rhythm in PER2 expression in the SCN was not altered in the $\mathrm{dKO}$ mice, although the photic induction of c-Fos was attenuated. Behaviorally, the dKO mice exhibited extremely disrupted daily rhythms in wheel-running behavior. In a light/dark cycle, some of the $\mathrm{dKO}$ mice were arrhythmic, whereas others expressed a diurnal rhythm with low amplitude and significant activity during the day. When placed in constant darkness, the dKO mice exhibited lowamplitude, fragmented rhythms and attenuated light responses. Together, these data are consistent with the hypothesis that the FDR current is critical for the generation of robust circadian rhythms in behavior as well as the synchronization of the circadian system to the photic environment.

\section{Introduction}

Daily biological rhythms are endogenously generated, regulated, and synchronized by networks of circadian oscillators communicating throughout the brain and periphery. In mammals, the suprachiasmatic nucleus (SCN) of the hypothalamus contains the "master" oscillatory network necessary for coordinating these rhythms. Neurons within the SCN also generate robust, synchronized rhythms in the transcription, translation, and degradation of key "clock genes" in an autoregulatory loop that has an endogenous periodicity of $\sim 24 \mathrm{~h}$ (Maywood et al., 2007; Takahashi et al., 2008). The SCN has been shown to generate neural activity rhythms in isolation from the rest of the organism in both the brain slice and dispersed cell culture preparations (Welsh et al., 2010). These studies are consistent with the idea that many SCN neurons are stable, self-sustained oscillators that have the intrinsic capacity to generate circadian rhythms in electrical activity. These neural activity rhythms are found in a variety of species (Block et al., 1996; Sheeba et al., 2008) and are likely to be central to the function of the circadian timing system (Schwartz et al., 1987; Yamaguchi et al., 2003).

Received Nov. 3, 2010; revised Dec. 3, 2010; accepted Dec. 12, 2010.

Mice were generously provided by Dr. B. Rudy (New York University). We thank Dr. D. Weaver for use of his facilities at University of Massachusetts for the in situ hybridization experiments. We thank Dr. M. Levine and Janelle Asai for support and help with the mouse breeding. Finally, we thank A. Vosko for his comments on an early draft of this manuscript and D. Crandall for assistance with the graphics.

*T.K. and D.H.L. contributed equally to this work.

Correspondence should be addressed to Christopher S. Colwell, Department of Psychiatry and Biobehavioral Sciences, University of California, Los Angeles, 760 Westwood Plaza,Los Angeles, CA 90024. E-mail: ccolwell@mednet.ucla.edu.

D0I:10.1523/JNEUROSCI.5792-10.2011

Copyright $\odot 2011$ the authors $\quad 0270-6474 / 11 / 312746-10 \$ 15.00 / 0$
During the day, SCN neurons are spontaneously active, whereas during the night, these cells are electrically silent. A set of currents are certainly responsible for this daily rhythm (for review, see Schaap et al., 2003; Kuhlman and McMahon, 2006; Ko et al., 2009). Conceptually, it can be useful to divide the ionic mechanisms to those currents responsible for the daily rhythm in membrane potential from those responsible for allowing SCN neurons to generate regular action potentials (APs) (Kuhlman and McMahon, 2006). Among this latter group of currents involved in modulation of firing frequency, the fast delayed rectifier (FDR) potassium $\left(\mathrm{K}^{+}\right)$currents is of particular interest because the magnitude of this current exhibits a circadian rhythm and the pharmacological blockade of the FDR current reduces the magnitude of the daily rhythm in firing in a brain slice preparation (Itri et al., 2005). More work is required to clarify the functional role of the FDR current in both modulation of firing rate in the SCN and, more broadly, on circadian behavior.

Toward this goal, we first sought to determine whether the expression of the Kv3.1 and Kv3.2 channels are lost in mice deficient in Kcnc1 and Kcnc2 genes [double knock-out (dKO)]. We also examined the magnitude of the FDR current in SCN neurons in the $\mathrm{dKO}$ mice. Next, we sought to determine whether $\mathrm{dKO}$ mice exhibit reduced spontaneous firing during the day as well as reduced NMDA-evoked firing during the night. We measured the basic rhythm in PER2 expression as well as the ability of light to evoke c-Fos expression in the SCN of these dKO mice. Finally, we examined the daily rhythms and photic regulation of wheelrunning activity in the $\mathrm{dKO}$ mice. Together, these experiments examine the impact of the loss of Kcnc (Shaw-related subfamily) genes on $\mathrm{Kv} 3$ expression and excitability in SCN neurons and 
provide a functional understanding of how the FDR current contributes to the physiological properties of the circadian timing system.

\section{Materials and Methods}

Animals. The experimental protocols used in this study were approved by the University of California, Los Angeles (UCLA) Animal Research Committee and all recommendations for animal use and welfare, as dictated by the UCLA Division of Laboratory Animals and the guidelines from the National Institutes of Health, were followed. To obtain mice homozygous for the Kcnc1 and Kcnc2 gene mutations on the ICR background, heterozygous male offspring of $\mathrm{Kcnc1}^{-/+}$mice (Ho et al., 1997) were interbred with homozygote $\mathrm{Kcnc} 2^{-/-}$mice (Lau et al., 2000). Both lines of mice were initially provided by Dr. Bernardo Rudy (New York University, New York, NY). The resulting offspring were genotyped, and $\mathrm{Kcnc1}^{-/-} ; \mathrm{Kcnc2}^{-1-} \mathrm{dKO}$ mice were used. The genotype of the mice was determined using genomic tail DNA and PCR. Because this breeding does not produce true wild-type (WT) littermates, we used age-matched $\mathrm{Kcnc2}^{-/-}$single knock-out (sKO) littermates as our controls throughout this study. In some cases, we examined data from C57BL/6 (WT) mice for comparison. The dKO mice backcrossed onto the C57BL/6 line showed extremely low fecundity and were not used in this study.

Behavioral analysis. Methods included were similar to those described previously (Colwell et al., 2003, 2004). Male mice, at least 8 weeks of age, were housed individually, and their wheel-running activity was recorded as revolutions per $3 \mathrm{~min}$ interval. The running wheels and data acquisition system were obtained from Mini Mitter. The animals were exposed to a $12 \mathrm{~h}$ light/dark cycle (LD) (light intensity, 300 lux) for 2 weeks. For some mice, the LD cycle was shifted $6 \mathrm{~h}$ earlier or $6 \mathrm{~h}$ later, and the number of cycle required for resynchronization was measured. Some mice were place in "skeleton" photoperiods consisting of $1 \mathrm{~h}$ of light followed by $23 \mathrm{~h}$ of dark, or $1 \mathrm{~h}$ of light followed by $11 \mathrm{~h}$ of dark. Then the animals were placed into constant darkness (DD) to assess their freerunning activity pattern. Some mice in DD were exposed to a brief light treatment (white light, 100 lux, $10 \mathrm{~min}$ ) at circadian time (CT) 16, with CT 12 defined by the locomotor activity onset. After each treatment, the animals were allowed to free-run undisturbed in DD for $14 \mathrm{~d}$. Phase shifts in the activity rhythm were determined by measuring the phase difference between eye-fitted lines connecting the onset of activity for a period of $10 \mathrm{~d}$ before and $10 \mathrm{~d}$ after an experimental manipulation. Measurements were made by investigators "blind" to the experimental group. Stimulus intensity (lux) was measured with a light meter (BK Precision). All handling of animals was performed in either the light portion of the LD cycle or DD with the aid of night-vision goggles (FJW Industries).

The locomotor activity rhythms of mice were analyzed by periodogram analysis combined with $\chi^{2}$ test with $p=0.05$ significance level (El Temps) on the raw data. The periodogram shows the amplitude (= power) of periodicities in the time series for all periods of interest (between 20 and $31 \mathrm{~h}$ in $3 \mathrm{~min}$ steps). The power values were normalized to the percentage of variance derived from the $Q p$ values of the periodogram $(Q p \times 100 / N$, where $N$ is the total number of data points) according to the calculated $p=0.05$ significance level. During DD, we found that a power value of $>30 \%$ indicated a strong and coherent activity rhythm. Slopes of an eye-fitted line through the onsets were also used to confirm period estimates made with the periodogram analysis. To estimate the cycle-to-cycle variability in activity onset, a linear regression to 15 cycles of onset of activity was calculated. The onset of activity for each cycle was defined as the phase at which the animal's activity levels first equaled the mean activity level for that cycle. The divergence between the measured and predicted onsets by linear regression was then determined, and the average difference was calculated for each animal. The duration of each cycle devoted to wheel-running activity is designated $\alpha$, whereas the duration of non-wheel-running activity is designated $\rho$. To measure these parameters, the average pattern of activity (i.e., the form estimate) was determined at modulo-period for each animal in DD for 15 cycles. Then for each waveform, $\alpha$ was calculated as the time during which the motor activity was above the medium. Fragmentation was analyzed by Clock Lab (Actimetrics). For this analysis, the max gap was set to $21 \mathrm{~min}$ and threshold was set to three counts per minute.
Brain slice preparation for electrophysiology. Methods included were similar to those described previously (Colwell, 2000, 2001). Male mice, at least $21 \mathrm{~d}$ of age, were used. Animals were killed between Zeitgeber time (ZT) 2-3 in the LD cycle for recording during the day and ZT 14-15 for recording during the night. When necessary, mice were killed in darkness. In all cases, mice were killed $1 \mathrm{~h}$ before recording. Brain slices were prepared using standard techniques from mice (C57BL/6, sKO, and $\mathrm{dKO}$ ) between $30-50 \mathrm{~d}$ of age. Mice were killed by isoflurane (Phoenix Pharmaceutical) anesthesia and rapidly decapitated. To prepare SCN cultures, the brain was quickly excised from the skull and placed in chilled low-calcium artificial CSF (ACSF) [in mu: $26 \mathrm{NaHCO}_{3}, 1.25$ $\mathrm{NaH}_{2} \mathrm{PO}_{4}, 10$ glucose, $125 \mathrm{NaCl}, 3 \mathrm{KCl}, 5 \mathrm{MgCl}_{2}$, and $1 \mathrm{CaCl}_{2}, \mathrm{pH} 7.2-7.4$ (290-310 mOsm)]. After chilling (5 min), the brain was trimmed to a block containing the hypothalamus and optic nerves. The brain was sliced in the coronal plane on a vibratome (Dosaka EM) at a thickness of $300 \mu \mathrm{m}$. The slices were kept in aerated $\left(95 \% \mathrm{O}_{2} / 5 \% \mathrm{CO}_{2}\right)$ ACSF [in mм: $26 \mathrm{NaHCO}_{3}, 1.25 \mathrm{NaH}_{2} \mathrm{PO}_{4}, 10$ glucose, $125 \mathrm{NaCl}, 3 \mathrm{KCl}, 2 \mathrm{MgCl}_{2}, 2$ $\left.\mathrm{CaCl}_{2}, \mathrm{pH} 7.2-7.4(290-310 \mathrm{mOsm})\right]$ at room temperature (30-60 min) before being transferred to an electrophysiological recording chamber.

Whole-cell patch-clamp electrophysiology. Methods included were similar to those described previously (Itri et al., 2005, 2010; Michel et al., 2006). Slices were placed in a recording chamber (PH-1; Warner Instruments) attached to the stage of a fixed-stage upright differential interference contrast (DIC) microscope (Olympus). The slices were superfused continuously ( $2 \mathrm{ml} / \mathrm{min}$ ) with ACSF aerated with $95 \% \mathrm{O}_{2} / 5 \% \mathrm{CO}_{2}$. The whole-cell patch-clamp recordings from the SCN were taken with recording electrodes. These micropipettes (typically 4-7 M $\Omega$ ) were pulled from glass capillaries (WPI) on a multistage puller (P-97; Sutter Instruments) and filled with the standard solution. The standard solution contained the following (in mM): $112.5 \mathrm{~K}$-gluconate, 1 EGTA, 10 HEPES, 5 MgATP, 1 GTP, 0.1 leupeptin, 10 phosphocreatine, $4 \mathrm{NaCl}, 17.5 \mathrm{KCl}, 0.5$ $\mathrm{CaCl}_{2}$, and $1 \mathrm{MgCl}_{2}$. The $\mathrm{pH}$ was adjusted to $7.25-7.3$, and the osmolality was adjusted between 290 and 300 mOsm. Recordings were obtained with AXOPATCH 200B amplifier (Molecular Devices) and monitored online with pClamp (version 9.2; Molecular Devices). To minimize changes in offset potentials with changing ionic conditions, the ground path used a $\mathrm{KCl}$ agar bridge. Each of the cells was determined to be within the SCN by directly visualizing the location of the cell with DIC microscopy. Cells were approached with slight positive pressure $\left(2-3 \mathrm{~cm} \mathrm{H}_{2} \mathrm{O}\right)$. The pipette was lowered to the vicinity of the membrane while maintaining positive pressure. After forming a high-resistance seal (2-10 G $\Omega$ ) by applying negative pressure, a second pulse of negative pressure was used to break the membrane.

The access resistance of these cells ranged from 15 to $35 \mathrm{M} \Omega$ in the whole-cell voltage-clamp configuration, whereas the cell capacitance was typically between 6 and $18 \mathrm{pF}$. Data were not collected if access resistance was $>40 \mathrm{M} \Omega$ or if the value changed significantly $(>20 \%)$ during the course of the experiment. In these studies, we used a 70\% compensation using positive feedback correction. The junction potentials between the pipette and the extracellular solution were cancelled by the voltage offset of the amplifier before establishing a seal and were not further corrected. Series and input resistance were monitored repeatedly by checking the response to small pulses in a passive potential range. The standard extracellular solution used for all experiments was ACSF. Drug treatments were performed by dissolving pharmacological agents in the ACSF used to bathe the slices during recording. Solution exchanges within the slice were achieved by a rapid gravity feed delivery system.

Currents traces were recorded with pClamp using the whole-cell voltage-clamp recording configuration and then analyzed using Clampfit (version 9.2; Molecular Devices). FDR $\mathrm{K}^{+}$currents were isolated pharmacologically using a voltage-step protocol in the whole-cell voltage-clamp configuration. The protocol consisted of a $100 \mathrm{~ms}$ prepulse at $-90 \mathrm{mV}$ (to elicit maximal conductance), followed by $250 \mathrm{~ms}$ steps at progressively depolarized potentials $(-80$ to $30 \mathrm{mV}, 10 \mathrm{mV}$ steps). Leak subtraction was performed during acquisition using a $\mathrm{p} / 4$ protocol, which uses four subpulses with one of four of the test pulse amplitude and reversed polarity given from a holding potential of -70 $\mathrm{mV}$. Current traces from treatment were subtracted from control to isolate FDR currents. 4-Aminopyridine (4-AP) (Sigma-Aldrich) was 
used to isolate FDR currents. Current measurements were performed in control solution and after 5 min of drug treatment in each cell. Spontaneous firing rate (SFR) were recorded with pClamp for 3 min using current clamp in the whole-cell patch configuration. No current was injected during recording.

Cell-attached patch-clamp electrophysiology. For the cell-attached recording, the patch electrode was filled with the bath solution. The spike counts always began only after stable recordings were made. At least 1 min of spontaneous firing rate was counted before the application of drugs.

Drug application for electrophysiology. The ACSF perfusion solution contained bicuculline $(25 \mu \mathrm{M})$ to block $\mathrm{GABA}_{\mathrm{A}}$-mediated currents, tetrodotoxin (TTX) $(0.5 \mu \mathrm{M}$; Sigma-Aldrich) to block fast voltage-activated sodium channels, and cadmium ( $25 \mu \mathrm{m}$; Sigma-Aldrich) to block voltage-activated calcium channels. NMDA ( $25 \mu \mathrm{M}$; Sigma-Aldrich) was applied in the bath for 3 min using bath application, and changes in firing rate were measured. The specificity of the NMDA-evoked changes in firing rate was assessed with the antagonist $\mathrm{D}(-)-2-$ amino-5-phosphonopentanoic acid (AP-5) (50 $\mu \mathrm{M}$; Sigma-Aldrich). We compared the magnitude of NMDA-evoked changes in firing rate in $\mathrm{WT}$, sKO, and $\mathrm{dKO}$ mice.

Immunohistochemistry. The methods were similar to those previously described (Wang et al., 2009; Dragich et al., 2010). Male mice of WT, sKO and dKO, 2-7 months of age, were used. Mice were anesthetized by Isoflurane (Phoenix Pharmaceutical, Burlingame, CA) and perfused with phosphate-buffered saline (PBS, pH 7.4) with heparin (2 units/ml, Henry Schein, Melville, NY) followed by $4 \%(\mathrm{w} / \mathrm{v})$ paraformaldehyde (Sigma-Aldrich) in PBS ( $\mathrm{pH}$ 7.4). Brains were dissected, post-fixed at $4^{\circ} \mathrm{C}$ overnight, and cryoprotected in $20 \%$ sucrose in PBS (pH 7.4). Immunohistochemistry

(IHC) was performed on free-floating $20 \mu \mathrm{m}$ cryostat (Thermo Fisher Scientific) coronal brain sections. Sections were washed for $5 \mathrm{~min}$ with PBS ( $\mathrm{pH} 7.4$, three times) and then incubated in PBS $\left(3 \% \mathrm{H}_{2} \mathrm{O}_{2}, 10 \%\right.$ methanol, $10 \mathrm{~min}$ ). Sections were then washed again in PBS (three times), dipped in 3\% normal goat serum in PBS with $0.1 \%$ Triton X-100 for $1 \mathrm{~h}$, and then incubated with a rabbit anti-Kv3.1 (1:200), anti-Kv3.2 (1:75; Alomone Labs), anti-c-Fos (1:30,000; Merck), or a rabbit anti-PER2 antiserum (1:1000; Alpha Diagnostics) in PBS (3\% normal goat serum, $0.1 \%$ Triton X-100) at $4^{\circ} \mathrm{C}$ overnight. Sections were washed in PBS (three times) and then incubated with biotinylated goat anti-rabbit antibody at 1:200 for $2 \mathrm{~h}$. Sections were washed again for $5 \mathrm{~min}$ in PBS (five times) and dipped in avidin-biotin solution (Vector Laboratories) for $45 \mathrm{~min}$, washed again in PBS (three times), and then placed in filtered $0.05 \% 3,3^{\prime}$ diaminobenzidine in Tris-buffered saline (TBS) containing a 1:800 dilution of $1.3 \% \mathrm{H}_{2} \mathrm{O}_{2}$. After sufficient color reaction (5-6 min), sections were washed with TBS and mounted on slides immediately. Sections were then dried overnight, dehydrated with ascending concentrations of ethanol, and coverslipped. Images were captured with Axio Vision camera systems (Carl Zeiss). Control experiments in which the primary antibody was not added did not exhibit any positive staining.

In situ hybridization. Brains were collected from C57BL/6J mice at CT 6 and 14 on the first day in constant darkness, and $15 \mu \mathrm{m}$ cryostat sections were collected as a one-in-eight series through the hypothalamus. In situ hybridization (ISH) was performed as described (Shearman et al., 1997). ${ }^{35}$ S-labeled antisense and sense cRNA probes were generated with the following sequences: mouse Per1 (nucleotides 340-761 of
GenBank accession number AF022992), mouse Kcnc1 (nucleotides 161594 of GenBank accession number BC132439; this probe detects both Kv3.1a and Kv3.1b), rat Kcnc2 (nucleotides 136-642 of GenBank accession number M34052; 93\% identical to mouse Kv3.2 nucleotide sequence). SCN optical density (OD) values from film autoradiographs were determined using NIH Image.

Statistical measurements. The datasets were analyzed by tests for equal variance and normal distribution to help select the appropriate test. Student's $t$ test or Mann-Whitney rank sum test were used for the ISH data. The remainder of the datasets was analyzed by one-way or two-way ANOVA. If significant group differences were detected by the ANOVA, then a post hoc analysis was applied. For all tests, values were considered significantly different if $p<0.05$. All tests were performed using SigmaStat (version 3.5; Systat Software). Values were shown as mean \pm SEM.

\section{Results}

$\mathrm{Kv} 3.1$ and Kv3.2 message is expressed in the SCN

The Kv3 (Shaw-related) family of $\mathrm{K}^{+}$channels is thought to be primarily responsible for generation of the FDR current (Rudy and McBain, 2001). To determine whether these genes are expressed in the SCN, we used ISH to measure Kcncl (Kv3.1) and Kcnc2 (Kv3.2) message in the mouse SCN. Expression of transcripts for Kv3.1 and Kv3.2 was observed throughout the SCN (data not shown). The sense probe for Kcncl did not exhibit labeling in the SCN under identical hybridization conditions, 


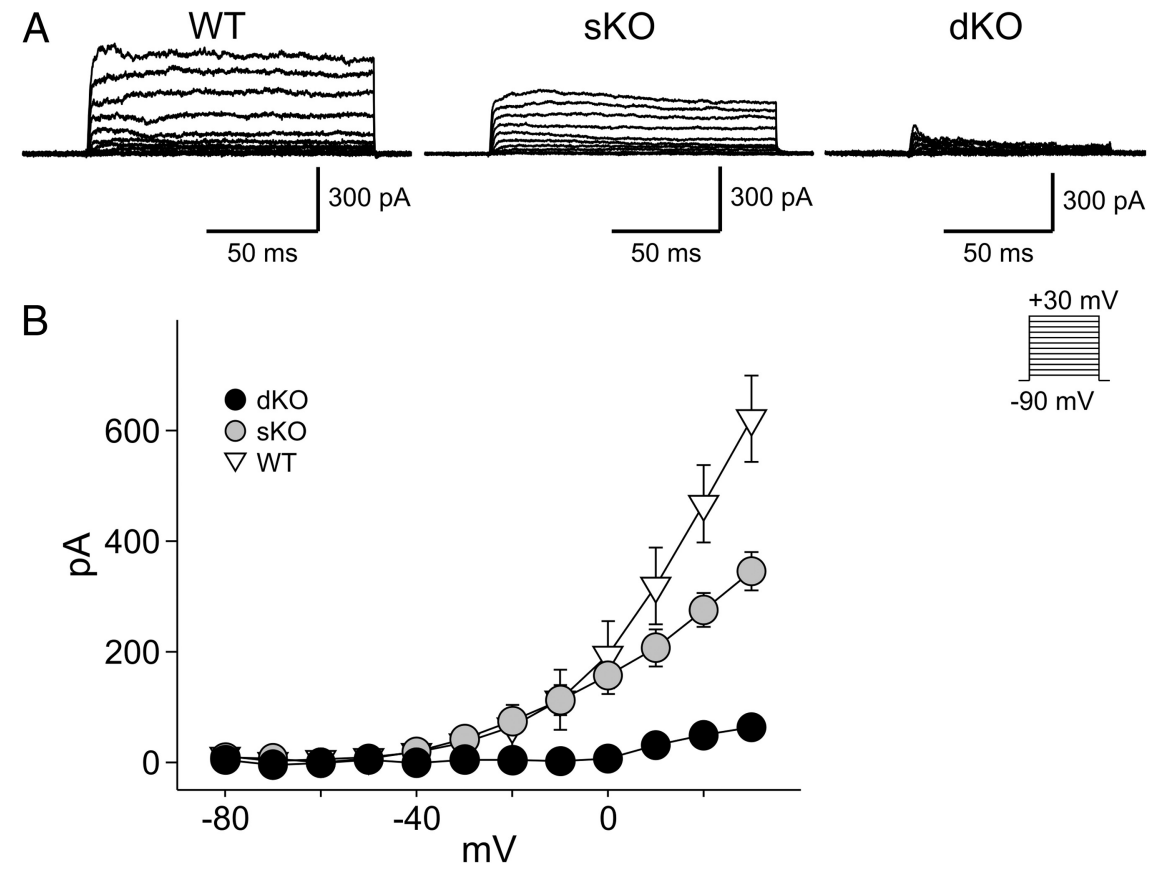

Figure 2. The magnitude of the FDR currents in $\mathrm{SCN}$ neurons is greatly reduced in dKO mice. Whole-cell patch-clamp recordings were made from dorsal $\mathrm{SCN}$ neurons. The FDR currents were isolated by subtraction (control, $0.5 \mathrm{~mm} 4$ 4-AP) using a voltage step protocol with a prepulse potential of $-90 \mathrm{mV}$ and test pulse potentials (see Materials and Methods). $A$, Examples of FDR current traces isolated by subtracting currents recorded in the presence of 4-AP from those recorded under control conditions. $\boldsymbol{B}$, Currentvoltage relationship of FDR currents in the SCN neurons from mice of the three genotypes: WT, sKO, and dKO. Data are shown as means \pm SEM. ${ }^{*} p<0.05$ as measured by one-way ANOVA followed by Holm-Sidak test for multiple comparisons. Recordings were all made during the day (ZT $4-6)$.

whereas the sense probe for Kcnc2 did exhibit some weak staining in the SCN (data not shown). Both transcripts also showed strong expression in the cortex and selected regions of the thalamus. Analysis of the OD measurements of Kv3.1 but not Kv3.2, expression (normalized to background) indicated that the levels of expression were higher in the SCN in the night (CT 14) than in the day (CT 6). For Kv3.1, the average OD measurements in the day were $0.33 \pm 0.03(n=6)$ and $0.43 \pm 0.07(n=5)$ in the night ( $t$ test; $t=-3.47, p=0.007)$. For Kv3.2, the average OD measurements in the day were $0.36 \pm 0.05(n=6)$ and $0.32 \pm 0.02$ $(n=5)$ in the night $(t$ test; $t=1.52, p=0.163)$. Adjacent sections through the SCN were hybridized with a probe to detect Per1, and these sections revealed the expected high-amplitude rhythm of Perl gene expression. The mean OD of Perl was higher in the day (CT 6, $0.61 \pm 0.05, n=5$ ) than in the night (CT 14, $0.20 \pm$ $0.01, n=6$; Mann-Whitney rank sum test, $p<0.004$ ). These Per1 data have been reported previously (Kim et al., 2009) and are shown here for reference only, to verify the presence of molecular rhythmicity in the SCN of the specimens used to examine Kv3.1 and Kv3.2.

\section{Expression of Kv3.1b and Kv3.2 channels in the SCN are lost in mice deficient in Kcnc1 and Kcnc2 genes}

We sought to determine whether the expression of the Kv3.1 and Kv3.2 channels are lost in mice deficient in Kcnc1 and Kcnc2 genes $(\mathrm{dKO})$. To examine the pattern of expression of these channels in the SCN, antibodies raised against Kv3.1b and Kv3.2 channels were used (Fig. 1). Mice were perfused in the day (ZT 6), and sections containing the SCN were examined using IHC. In WT mice, the pattern of expression within the SCN was similar to that described previously (Itri et al., 2005). The mice deficient in Kcnc2 (sKO) lacked expression of the Kv3.2 channel, and, critically, the mice deficient in Kcncl and Kcnc2 (dKO) lacked expres- sion of both Kv3.1b and Kv3.2 channels. These data confirm expression of both channels within the SCN as well as validates the use of the transgenic mice to explore the function of these channels.

\section{The magnitude of the FDR current is greatly reduced or eliminated in the dKO mice}

We used the whole-cell voltage-clamp technique to isolate and record FDR currents from neurons in the mouse SCN (Fig. 2). The ACSF perfusion solution contained bicuculline $(25 \mu \mathrm{M})$, TTX $(0.5$ $\mu \mathrm{M})$, and cadmium $(25 \mu \mathrm{M})$. The intracellular solution contained BAPTA (1 mM). Each of these cells was determined to be within the dorsal region of the SCN by directly visualizing the location of the cell with infrared DIC video microscopy. The FDR currents were isolated by subtraction (control, $0.5 \mathrm{~mm}$ 4-AP) using a voltage step protocol (Martina et al., 1998; Wang et al., 1998) with a prepulse potential of $-90 \mathrm{mV}$ and test pulse potentials. We recorded this current from SCN neurons in mice of three genotypes: WT $(n=10)$, sKO $(n=20)$, and dKO $(n=14)$. Oneway ANOVA detected significant variation between genotypes $\left(F_{(2,41)}=37.00\right.$, $p<0.01)$. Measured at the peak $(+30$ $\mathrm{mV}$ ), the FDR currents in sKO were significantly lower than WT (Holm-Sidak test, $t=4.510, p<0.05$ ) and $\mathrm{dKO}$ was significantly lower than sKO (Holm-Sidak test, $t=5.133, p<0.05$ ) (Fig. 2). In the $\mathrm{dKO}$ mice, there was no measureable FDR current until the voltage was stepped to $+10 \mathrm{mV}$. At these positive voltage steps $(+10,20,30 \mathrm{mV})$, there was a small remainder current detected that was $\sim 10 \%$ of the magnitude of the FDR current recorded in the SCN of WT mice. Therefore, the magnitude of FDR current in SCN neurons was dramatically reduced, but perhaps not eliminated, in mice lacking both Kv3.1 and Kv3.2 channels.

\section{Excitability of SCN neurons is reduced in the dKO mice}

Using the current-clamp recording technique in the whole-cell configuration (Fig. 3), we measured the SFR in dorsal SCN neurons from three genotypes: WT $(n=27), \operatorname{sKO}(n=24)$, and dKO $(n=20)$. Recordings (3 min) were made during the day (ZT 4-6) and night (ZT 14-16), and the resulting data were analyzed by two-way ANOVA. This analysis revealed a significant effect of time of day $\left(F_{(1,71)}=50.90, p<0.001\right)$ and genotype $\left(F_{(2,71)}=\right.$ $5.14, p=0.008)$ as well as a significant interaction between time of day and genotype $\left(F_{(2,71)}=8.20, p<0.001\right)$. As expected, the SFR of WT mice was significantly [post hoc Fisher's least significant (LSD) test, $p<0.001$ ] higher during the day $(7.0 \pm 0.6 \mathrm{~Hz}$, $n=12)$ than during the night $(2.2 \pm 0.5 \mathrm{~Hz}, n=15)$. The SFR of sKO was indistinguishable from the WT mice, with SFR during the day $(7.0 \pm 0.5 \mathrm{~Hz}, n=12)$ being significantly higher ( post hoc Fisher's LSD test, $p<0.001)$ than the night $(2.3 \pm 0.5 \mathrm{~Hz}, n=$ $12)$. In contrast, in the dKO mice, there were no significant differences ( $p$ ost hoc Fisher's LSD test, $p=0.532$ ) between SFR during the day $(3.2 \pm 0.8 \mathrm{~Hz}, n=11)$ and night $(2.7 \pm 0.5 \mathrm{~Hz}$, $n=15)$. The daytime SFR was significantly reduced in the dKO mice compared with either the sKO or WT mice ( post hoc Fish- 
A
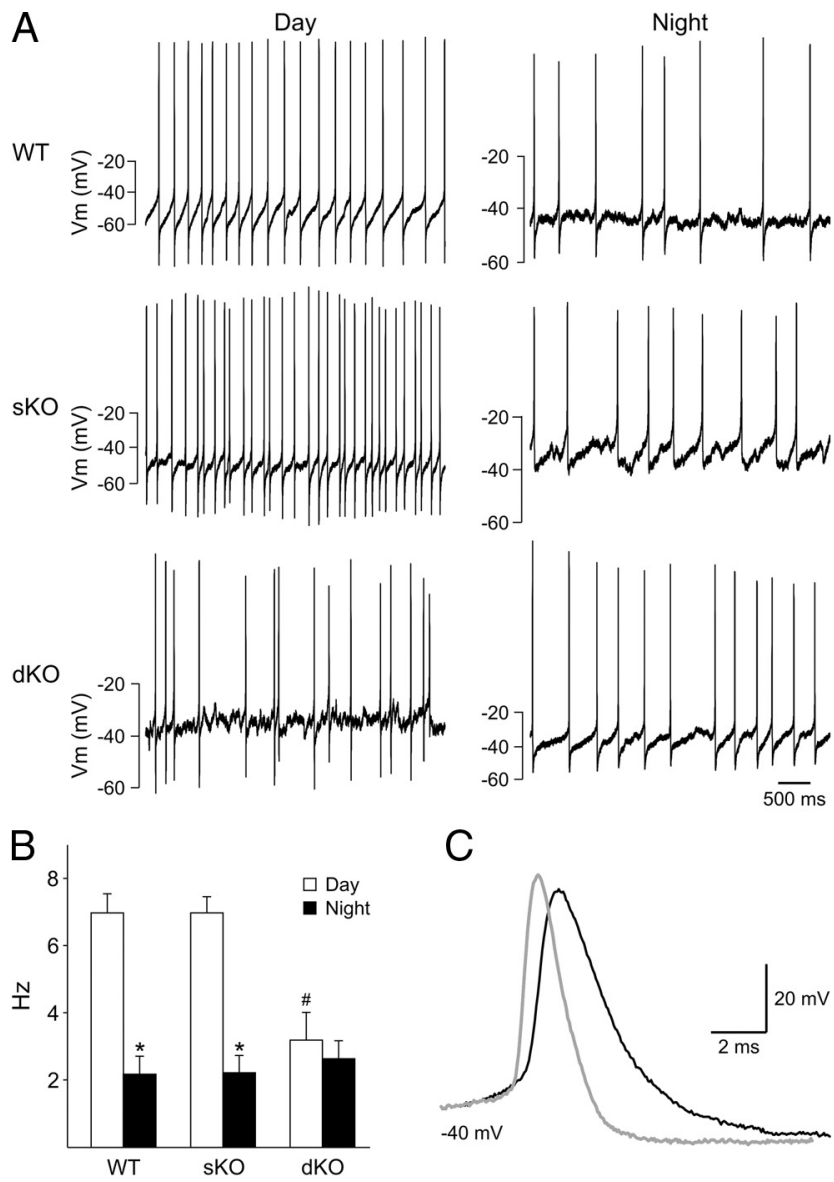

Figure 3. The daily peak of spontaneous firing rate in SCN neurons is reduced in the dKO mice. Using the current-clamp recording technique in the whole-cell configuration, we measured the SFR in dorsal SCN neurons during the day (ZT 4-6) and night (ZT 14-16). A, Representative examples of firing rate recorded during the day and night from each of the three genotypes: WT, sKO, and dKO. $B$, Average firing rate during the day and night for each genotype. Data are shown as means \pm SEM. ${ }^{*} p<0.01$ indicates significance difference between day and night SFR, analyzed by two-way ANOVA followed by Fisher's LSD post hoc comparison. \# indicates significance differences in daytime SFR by the same analysis. $C$, Representative examples illustrating that the action potential width and time required for repolarization are increased in dKO mice. Shape of the APs in the SCN of control sKO (gray line) and dKO (black line) mice. The dKO mice showed significant $(p<0.05)$ increases in spike width and decay time constants.

er's LSD test, $p<0.001$ ). In the early morning (ZT $0-4)$, there was no difference in the SFR recorded between the genotypes (WT, $2.8 \pm 0.4, n=33 ; \mathrm{dKO}, 2.7 \pm 0.4, n=24 ; p=0.089$ ). The width of the action potentials (Fig. $3 C$ ) were also significantly $(p<0.05)$ altered in the SCN of the $\mathrm{dKO}$ mice $(\mathrm{C} 57 \mathrm{BL} / 6,2.0 \pm$ $0.2 \mathrm{~ms}$; sKO, $2.1 \pm 0.2 \mathrm{~ms}$; dKO, $3.0 \pm 0.3 \mathrm{~ms}$ ). Thus, the lack of $K c n c 1$ and $K c n c 2$ genes appeared to eliminate the day/night difference in spontaneous activity in the SCN by reducing the firing rate during the mid-day peak.

Using the current-clamp recording technique in the cellattached configuration (Fig. 4), we measured the impact of bath application of NMDA $(25 \mu \mathrm{M}, 3 \mathrm{~min})$ on firing rate in ventral SCN neurons from three genotypes: WT $(n=22)$, sKO $(n=18)$, and $\mathrm{dKO}(n=11)$. Recordings were made during the night (ZT 14-16) when NMDA can cause phase shifts of the circadian rhythm of neural activity recorded from the SCN brain slice (Ding et al., 1994). If untreated, the firing rate was stable over the 10 min required to complete these experiments (data not shown). A comparison of NMDA-evoked responses in all three genotypes by two-way ANOVA revealed a significant effect of NMDA treat-
A

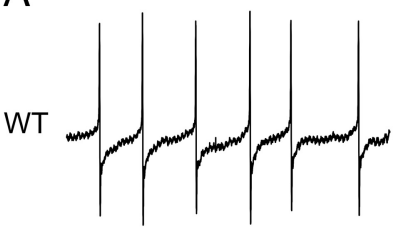

Control

NMDA
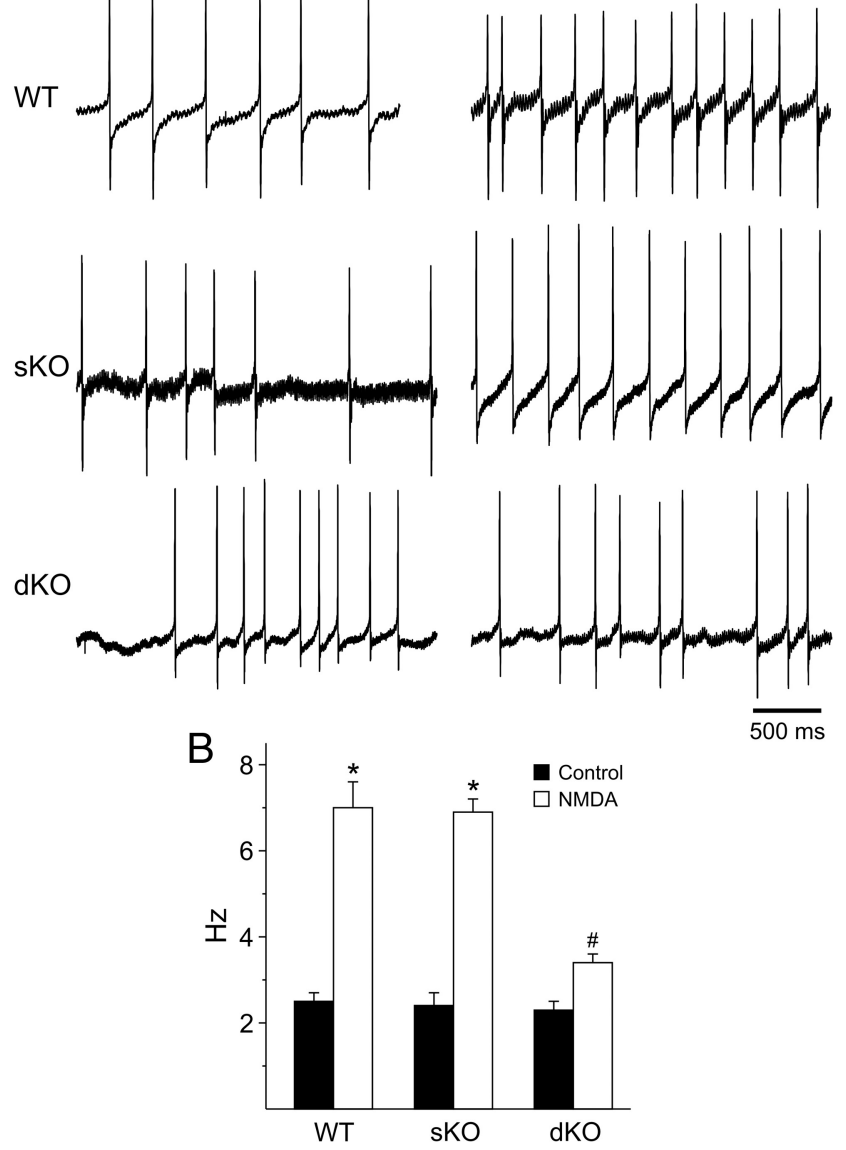

Figure 4. The NMDA-evoked increase in firing rate in SCN neurons is reduced in the dKO mice. Current-clamp recording were made in the cell-attached configuration to measure the firing rate in ventral $S C N$ neurons during the night (ZT 14-16). $A$, Representative examples of firing rate recorded before and after bath application of NMDA $(25 \mu \mathrm{m})$ from each of the three genotypes: WT ( $n=22)$, sKO $(n=18)$, and dKO $(n=13)$. $\boldsymbol{B}$, Average firing rate before and after treatment for each genotype. Data are shown as means with SEM. ${ }^{*} p<0.001$ indicates significance difference between firing rates before and after NMDA treatment, analyzed by two-way ANOVA followed by Tukey's test for multiple comparisons. \# indicates significant differences in NMDA-evoked firing rate by the same analysis.

ment $\left(F_{(1,51)}=93.78, p<0.001\right)$ and genotype $\left(F_{(2,51)}=10.67\right.$, $p<0.001)$ as well as a significant interaction between treatment and genotype $\left(F_{(2,51)}=8.95, p<0.001\right)$. In WT mice, the bath application of NMDA increased the firing rate from a baseline of $2.5 \pm 0.2$ to $7.0 \pm 0.5 \mathrm{~Hz}$ ( post hoc Tukey's test, $p<0.001$ ). In the presence of the competitive NMDA receptor antagonist AP-5 $(50 \mu \mathrm{M}, 120 \mathrm{~s})$, there was no significant change (paired $t$ test, $t=0.33, p=0.749)$ in the firing rate before $(2.7 \pm 0.7)$ or after $(2.6 \pm 0.7 \mathrm{~Hz})$ NMDA treatment. In sKO mice, NMDA treatment increased the firing rate from $2.4 \pm 0.3$ to $6.9 \pm 0.3 \mathrm{~Hz}$ ( post hoc Tukey's test, $p<0.001$ ). In contrast, in $\mathrm{dKO}$ mice, there was no significant change ( $p$ ost hoc Tukey's test, $p=$ $0.151)$ in the firing rate before $(2.3 \pm 0.2)$ or after $(3.4 \pm 0.3$ $\mathrm{Hz}$ ) NMDA treatment. So the lack of Kcnc1 and Kcnc2 genes also reduced the ability of NMDA to increase firing rate of SCN neurons during the night.

\section{PER2 expression is not altered in the SCN of dKO mice}

To determine whether the molecular machinery necessary to generate circadian oscillations was impacted by the loss of the Kcnc genes, we used IHC to examine PER2 protein expression 

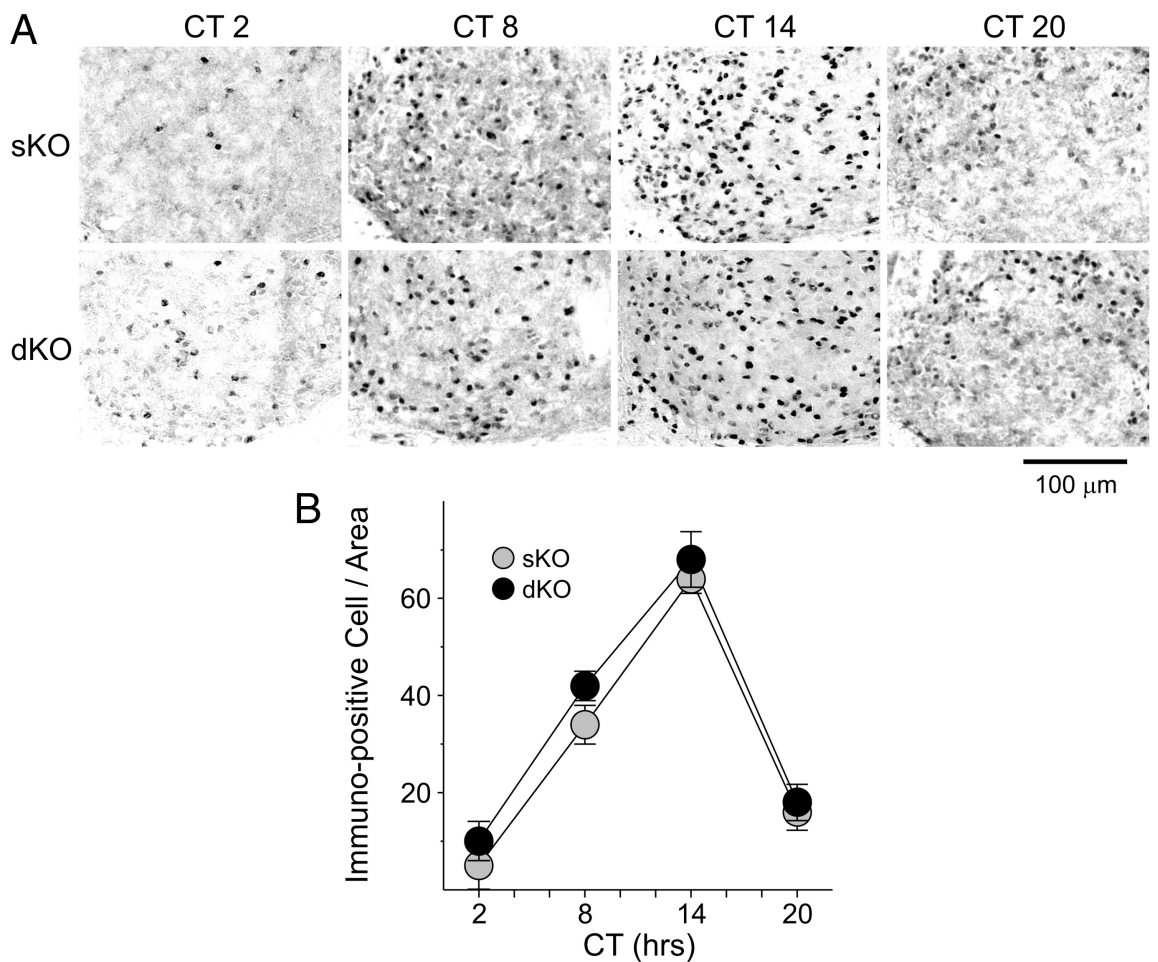

Figure 5. PER2 expression is not altered in the $S C N$ of $d K O$ mice. Mice were held in $D D$, and wheel-running activity was measured to determine circadian phase. IHC was used to measure PER2 expression in the SCN. $A$, Photomicrographs $(400 X)$ of PER2 immunoreactivity in tissue sections taken from mice killed during 4 phases of the daily cycle (CT 2, 8, 14, 20). Scale bar, 100 $\mu \mathrm{m} . \boldsymbol{B}$, Numbers of PER2 immunopositive cells in the $\mathrm{SCN}$ varied as a function of time of day with highest count in early night. Data are shown at means \pm SEM. The data were analyzed by two-way ANOVA, and no differences were found between the genotypes.

A
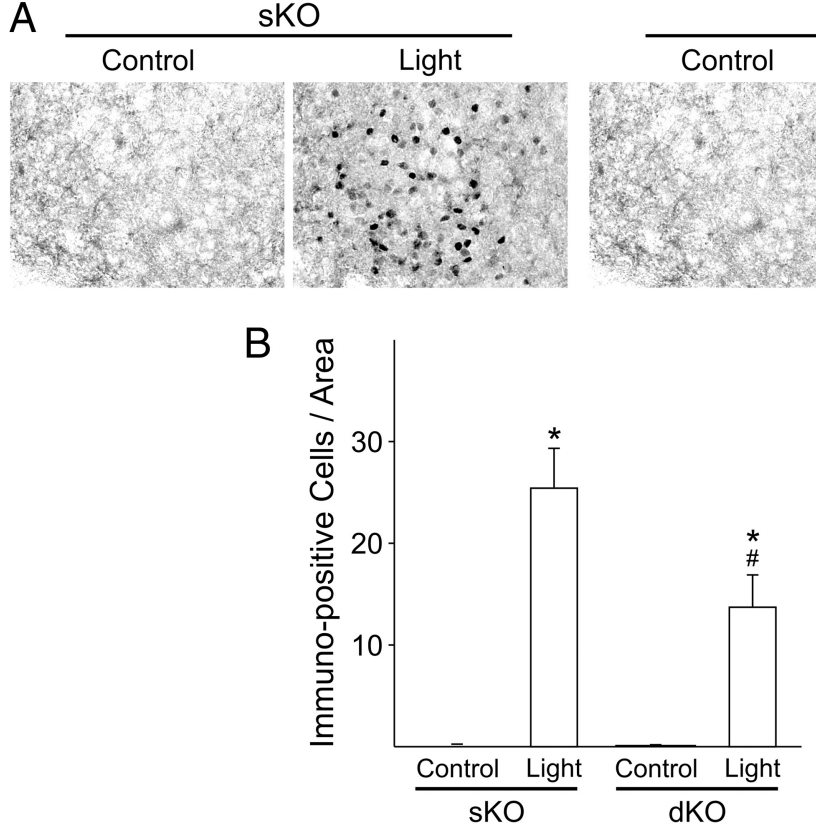

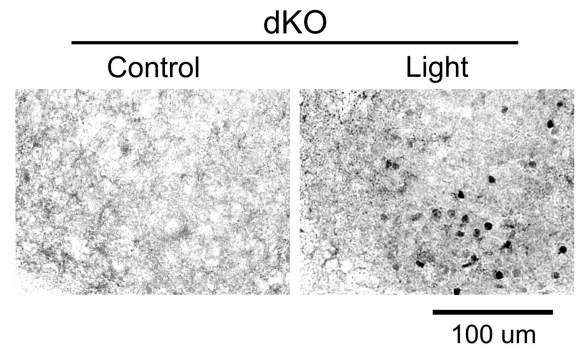

Figure 6. Light-induced increase in c-Fos expression in the SCN is reduced in dKO mice. Mice were held in DD, and wheelrunning activity was measured to determine circadian phase. Experimental mice were exposed to light (100 lux, 10 min) at CT 16, whereas controls were handled but not exposed to light. IHC was used to measure c-Fos expression in the SCN from tissue collected at CT 17. A, Photomicrographs ( $400 \times)$ of c-Fos immunoreactivity in tissue sections taken from mice of each genotype. Scale bar, $100 \mu \mathrm{m} . \boldsymbol{B}$, Numbers of c-Fos immunopositive cells in the SCN increased as a result of light exposure. Data are shown at means \pm SEM. ${ }^{*} p<0.01$ indicates significance difference in the number of c-Fos immunoreactive cells in the handled and light-treated groups, analyzed by two-way ANOVA followed by the Holm-Sidak test for multiple comparisons. \# indicates significance differences in light-treated groups by the same analysis. within the SCN. The wheel-running activity of sKO and $\mathrm{dKO}$ male mice in LD were monitored, and the mice were placed in DD for $3 \mathrm{~d}$. Mice ( $n=3-6$ per time point) from three genotypes (WT, sKO, dKO) were sampled at four different points in the daily cycle (CT 2, 8, 14, 20). PER2 was strongly expressed in the SCN of both sKO and $\mathrm{dKO}$ mice (Fig. $5 A$ ), with immunoreactivity seen throughout the SCN. The mean number of immunopositive neurons per SCN section varied with time of day (Fig. $5 B$ ), with peak counts found at early subjective night (CT 14) and low counts measured in the early subjective day (CT 2). A comparison of PER2 immunoreactivity at the peak and trough in all three genotypes by two-way ANOVA revealed a significant effect of time of day $\left(F_{(1,19)}=291.07, p<\right.$ $0.001)$ but no effect of genotype $\left(F_{(2,19)}=\right.$ $0.70, p<0.507)$ nor any significant interaction between time of day and genotype $\left(F_{(2,19)}=0.99, p=0.387\right)$. Thus, as measured by the PER2 rhythm, we do not see any evidence that the molecular clockwork is disrupted in the mutant mice.

\section{Light-induced gene expression in the $\mathrm{SCN}$ neurons is reduced in the dKO mice}

The light induction of c-Fos in the SCN is one of the most robust and wellcharacterized markers of photic regulation gene expression in the SCN (Kornhauser et al., 1990). Therefore, to determine whether light-induced translational response within the SCN is impaired in dKO mice, we used IHC to measure the number of c-Fos immunopositive cells within the SCN (Fig. 6). Again, we monitored wheel-running activity, and mice were placed in DD for $3 \mathrm{~d}$. Experimental mice (WT, $n=6$; $\mathrm{sKO}, n=6$; dKO, $n=$ 4) were then exposed to light (white light, 100 lux; $10 \mathrm{~min}$ duration) at projected CT 16, and tissue was collected 60 min after the beginning of the light treatment. Tissue from time-matched control mice (WT, $n=4$; sKO, $n=7$; $\mathrm{dKO}, n=7$ ) was also collected for comparison. Control experiments in which the primary antibody was not added, or the primary antibody was preabsorbed with a peptide control, did not exhibit any positive staining (data not shown). A comparison of c-Fos immunoreactivity in all three genotypes by two-way ANOVA revealed a significant effect of light treatment $\left(F_{(1,28)}=229.19, p<\right.$ $0.001)$ and genotype $\left(F_{(2,28)}=123.55\right.$, $p<0.001)$ as well as a significant inter- 

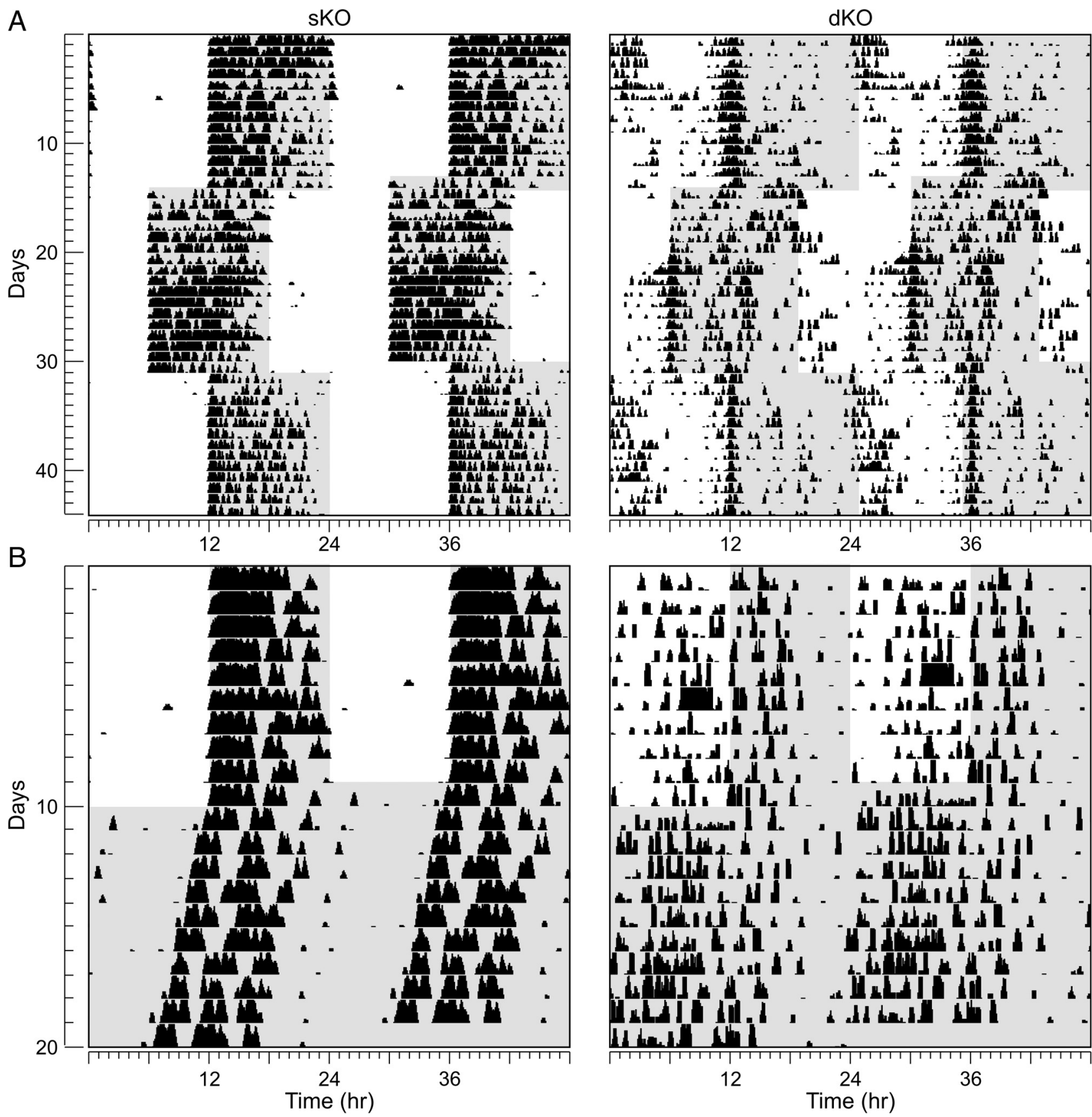

Figure 7. Diurnal and circadian rhythms of wheel-running behavior are severely disrupted in dK0 mice. Mice were placed individually in cages with wheel-running and locomotor activity recorded under different lighting conditions. Each horizontal row represents an activity record for a 24-h day. Successive days are plotted from top to bottom. Shaded panels represent the dark portion of the LD cycle. $\boldsymbol{A}$, Examples of the wheel-running activity recorded from sKO (left) and dKO (right) mice in LD (12/12 h) conditions and after $6 \mathrm{~h}$ phase shifts in the LD cycle. $\boldsymbol{B}$, Examples of wheel-running activity when mice are held in LD (12/12 h) and then released into DD.

action between treatment and genotype $\left(F_{(2,28)}=63.48, p<\right.$ $0.001)$. All genotypes displayed significant increases in the number of c-Fos-positive cells in the SCN after exposure to light at CT 16 when compared with untreated controls (post hoc Holm-Sidak test; WT, $t=17.17, p<0.001$; sKO, $t=5.91$, $p<0.001$; dKO, $t=2.62, p=0.014$ ) (Fig. 6). The magnitude of this light induction was significantly reduced in $\mathrm{dKO}$ mice when compared with sKO (Holm-Sidak test, $t=2.57, p=$ 0.016 ) or WT (Holm-Sidak test, $t=17.31, p<0.001$ ) mice. Therefore, the photic regulation of gene expression within the $\mathrm{SCN}$ is disrupted in the $\mathrm{dKO}$ mice.
Diurnal and circadian rhythms of wheel-running behavior are severely disrupted in the $\mathrm{dKO}$ mice

We used wheel-running activity to determine the impact of the loss of the Kcnc genes on diurnal and circadian rhythms of behavior (Fig. 7). In these studies, we compared locomotor activity rhythms in WT $(\mathrm{C} 57 \mathrm{BL} / 6, n=15)$ mice with locomotor activity measured in littermate sKO $(n=15)$ and dKO $(n=15)$ lines. Under LD conditions, the majority of Kv3 dKO mice (14 of 15 examined) continued to demonstrate weakly rhythmic wheelrunning behavior (Fig. 7). The overall levels of activity and the amplitude of the daily rhythm were significantly reduced (Table 
Table 1. Detailed analysis of activity data

\begin{tabular}{lccc}
\hline & C57BL/6 WT & Kv3.2 sK0 & Kv3.1/3.2 dKO \\
\hline LD 12/12 h & $(n=15)$ & $(n=15)$ & $(n=15)$ \\
Tau (h) & $24.0 \pm 0.01$ & $24.0 \pm 0.01$ & $24.0 \pm 0.02$ \\
Power (\% variation) & $58.69 \pm 1.72$ & $46.70 \pm 3.17$ & $20.65 \pm 1.70^{*, * *}$ \\
Activity (rev/h) & $407.59 \pm 27.9$ & $353.29 \pm 61.04$ & $79.28 \pm 12.94^{*, * *}$ \\
Activity in light (\%A) & $1.89 \pm 0.39$ & $5.12 \pm 1.19$ & $35.69 \pm 5.27^{*, * *}$ \\
Phase angle (min) & $0.12 \pm 0.66$ & $6.67 \pm 1.55$ & $330.36 \pm 90.51^{*, * *}$ \\
Precision & $0.11 \pm 0.02$ & $1.08 \pm 0.65$ & $2.99 \pm 0.55^{*, * *}$ \\
Fragmentation & $3.62 \pm 0.19$ & $6.24 \pm 0.43^{*}$ & $10.95 \pm 0.60^{*, * *}$ \\
Arrhythmic (\%) & $0 \%$ & $0 \%$ & $7 \%^{*, * * *}$ \\
Bimodal (\%) & $0 \%$ & $0 \%$ & $27 \%^{*, * *}$ \\
Active in day (\%) & $0 \%$ & $0 \%$ & $64 \%^{a, *, * *}$ \\
Entrainment to 6h adv (d) & $5.3 \pm 0.4$ & $3.9 \pm 0.8$ & $5.6 \pm 0.7$ \\
Entrainment to 6h delay (d) & $2.3 \pm 0.3$ & $1.5 \pm 0.6$ & $3.7 \pm 0.5^{* *}$ \\
LD 1/11/1/11 h & $(n=19)$ & $(n=8)$ & $(n=11)$ \\
Tau (h) & $24.0 \pm 0.7$ & $24.0 \pm 0.8$ & $24.1 \pm 4.5$ \\
Power (\% variation) & $53.55 \pm 2.86$ & $32.57 \pm 3.62$ & $16.02 \pm 1.22^{*}$ \\
Arhythmic (\%) & $0 \%$ & $0 \%$ & $36 \%^{*, * * *}$ \\
Bimodal (\%) & $0 \%$ & $0 \%$ & $45.50 \%^{*, * *}$ \\
LD 1/23 h & $(n=14)$ & $(n=10)$ & $(n=11)$ \\
Tau (h) & $24.0 \pm 0.03$ & $23.9 \pm 0.07$ & $24.0 \pm 0.02$ \\
Power (\% variation) & $49.10 \pm 4.21$ & $27.86 \pm 2.86^{*}$ & $22.44 \pm 3.28^{*}$ \\
Phase angle (min) & $23.12 \pm 1.65$ & $12.51 \pm 8.92$ & $-263.45 \pm 71.42$ \\
Arrhythmic (\%) & $0 \%$ & $0 \%$ & $8 \%^{*, * * *}$ \\
Bimodal (\%) & $0 \%$ & $0 \%$ & $18 \%^{*, * * *}$ \\
DD & $(n=14)$ & $(n=14)$ & $(n=14)$ \\
Tau (h) & $23.6 \pm 0.04$ & $23.5 \pm 0.06$ & $23.6 \pm 0.1$ \\
Power (\% variation) & $50.45 \pm 2.46$ & $29.89 \pm 2.79^{*}$ & $14.25 \pm 0.44^{*, * *}$ \\
DD activity (rev/h) & $394.75 \pm 37.27$ & $329.7 \pm 70.0$ & $71.4 \pm 13.2^{*, * *}$ \\
Precision & $0.25 \pm 0.06$ & $0.63 \pm 0.12$ & $2.79 \pm 0.57^{*, * *}$ \\
Fragmentation & $3.93 \pm 0.26$ & $8.95 \pm 0.67^{*}$ & $10.7 \pm 1.06^{*}$ \\
Arrhythmic (\%) & $0 \%$ & $0 \%$ & $14 \%^{*, * *}$ \\
Bimodal (\%) & $0 \%$ & $0 \%$ & $29 \%^{*, * * *}$ \\
CT16 phase delay (min) & $107.9 \pm 5.5$ & $72 \pm 6.9$ & $30 \pm 4.9^{*}$ \\
\hline
\end{tabular}

$a_{n}=14$ (1 mouse arrhythmic).

rev, Revolutions. ${ }^{*} p<0.05$ versus (57BL/6 WT; ${ }^{* *} p<0.05$ versus Kv3.2 sKO.

1). The dKO mice also showed strikingly more daytime activity than their sKO littermates and entrained with a positive phase angle (Table 1). We also examined the ability of the mice to resynchronize to shifts in the $\mathrm{LD}$ cycle. The Kv3 dKO mice took longer to resynchronize to a $6 \mathrm{~h}$ phase delay of the LD cycle than their Kv3 sKO littermates (Table 1). A significant subset of $\mathrm{dKO}$ mice ( 4 of 15) demonstrated a bimodal pattern of diurnal activity, which was not seen in any of the Kv3.2 sKO or C57BL/6 WT mice examined. To further explore this bimodal activity, mice were held under a skeleton photoperiod (1/11/1/11 h LD). Under these conditions, $46 \%$ of the $\mathrm{dKO}$ mice, but none of the sKO littermates, displayed a bimodal distribution of activity (data not shown). Under a skeleton photoperiod of 1/23 h LD, 9 of 11 examined Kv3 dKO mice showed an extremely positive phase angle of entrainment in which daily activity started well in advance of the daily hour of light (data not shown).

Under DD, most of the $\mathrm{dKO}$ mice (12 of 15) continued to express a circadian rhythm in wheel-running activity as measured by periodogram analysis (Fig. 7). There were no significant differences in the free-running period between the three genotypes examined (Table 1). As seen under LD conditions, the rhythms were low amplitude and fragmented (Table 1). To test the light input pathway, we subjected individual mice to light (white light, 100 lux; 10 min duration) at CT 16 and measured the resulting phase delay. The $\mathrm{dKO}$ exhibited a significantly reduced magnitude of light-induced phase shifts (Table 1). Together, our behavioral analysis suggests that the lack of Kcncl and Kcnc2 genes greatly impacts the ability of the circadian system to generate daily rhythms in wheel-running activity as well as the ability of light to regulate these rhythms.

\section{Discussion}

The $\mathrm{Kv} 3$ family of $\mathrm{K}^{+}$channels is thought to be primarily responsible for generation of the FDR current (Rudy and McBain, 2001). There are four genes that make up this family, including Kcnc1, Kcnc2, Kcnc3, and Kcnc4 (Weiser et al., 1994). In expression systems, the channels produced by the expression of Kcnc1 and $\mathrm{Kcnc2}$ produce delayed rectifier $\mathrm{K}^{+}$currents, whereas the expression of $\mathrm{Kcnc3}$ and $\mathrm{Kcnc4}$ produce inactivating A-type $\mathrm{K}^{+}$ currents (Rudy et al., 1999). The FDR current expressed in SCN neurons showed little inactivation (Itri et al., 2005), so we focused our attention on channels produced by Kcnc1 and Kcnc2. Data from the Allen Brain Bank shows strong expression of the transcript for Kcnc2 in the SCN with weak expression of Kcnc1 and Kcnc4 and no expression of Kcnc3 in this region (Lein et al., 2007). Previous work using DNA arrays indicated that Kcncl is expressed nonrhythmically in SCN tissue (Panda et al., 2002). In the present study, we used ISH to determine that both Kcncl and Kcnc2 are widely expressed within the SCN (data not shown). Importantly, we used IHC to demonstrate that mice deficient in Kcnc2 (sKO) lacked expression of the Kv3.2 channel and that mice deficient in both Kcnc1 and Kcnc2 (dKO) lacked expression of both the Kv3.1b and Kv3.2 channels (Fig. 1). We recorded the FDR current from SCN neurons and found that the loss of Kcnc2 modestly reduced the magnitude of the FDR current, whereas the loss of both $K c n c 1$ and Kcnc2 resulted in a dramatically reduced current (Fig. 2). As far as we are aware, this is the first time that the actual FDR current has been measured in neurons from these sKO and dKO mice. Our data does not exclude a role for Kv3.4 in the SCN because we did not directly examine the expression of these channels. It is possible that the small remainder current observed in the dKO (Fig. 2) is carried by this channel or that this channel shapes the properties of the FDR current (Baranauskas et al., 2003). Together, the present data provide compelling evidence that most of the FDR current in SCN neurons is carried by $\mathrm{Kv} 3.1$ and Kv3.2 channels and allow us to use the dKO mutants to explore the function of the FDR current in the circadian system.

The FDR current is known to exhibit a set of unique physiological properties, including high thresholds of activation, rapid activation, and large conductance in the SCN (Itri et al., 2005) as well as in many other brain regions (for review, see Rudy and McBain, 2001; Baranauskas, 2007; Joho and Hurlock, 2009). These properties enable neurons with this current to rapidly repolarize their membrane potential after generating an AP. Given this biophysical function, it is not surprising that Kv3 channels are preferentially found in neurons that generate sustained trains of APs at high frequencies (Rudy and McBain, 2001; Joho and Hurlock, 2009). However, it is worth pointing out that the Kcnc genes are widely expressed in the nervous system and it may be that FDR currents can serve other functions. For example, in the retina, Kv3.1 and Kv3.2 channels are expressed in starburst amacrine cells that are not fast spiking neurons and may serve to provide a voltage-dependent shunt that limits depolarization of the soma (Ozaita et al., 2004). SCN neurons are spontaneously active but are not fast spiking neurons. These cells generate AP with a peak frequency of $\sim 10-12 \mathrm{~Hz}$ during the day (for review, see Schaap et al., 2003; Kuhlman and McMahon, 2006; Ko et al., 2009). During the night, SCN neurons are normally silent but do respond to photic stimulation transduced by melanopsincontaining retinal ganglion cells that generate APs up to $20 \mathrm{~Hz}$ 
(Meijer et al., 1998; Berson et al., 2002; Warren et al., 2003; Tu et al., 2005; Irwin and Allen, 2007). In the present study, we examined the impact of the loss of the FDR current on the level of spontaneous activity during the daytime (Fig. 3) and the NMDAevoked responses during the night (Fig. 4). Under both conditions, we found that the excitability of SCN neurons was significantly reduced in the $\mathrm{dKO}$ mice. The width of the APs (Fig. $3 C$ ) as well as the time required for repolarization after an AP were increased in the $\mathrm{dKO}$ mice (data not shown) and are results that highlight the importance of the FDR current in the SCN even in the absence of a high firing rate. These physiological results provide important support for the hypothesis that the FDR current plays a critical role in generation of the daily rhythms in firing rate that are a hallmark feature of SCN neurons. These results also suggest that this current may be important for the ability of SCN neurons to respond to sensory stimulation.

We used wheel-running activity to determine the impact of the loss of the Kcnc genes on diurnal and circadian rhythm behavior (Fig. 7). Although we have a good understanding of some aspects of the circuit that is responsible for circadian rhythms, an important caveat to our behavioral analysis is that we cannot be confident of the anatomical site of action of the loss of these genes. Our data are consistent with the Kcnc genes having a key role in the light response of the circadian system. The dKO mice showed increased daytime activity and extremely positive phase angle of entrainment in an LD cycle as well as a bimodal distribution of activity in a skeleton LD cycle (Fig. 7, Table 1). When exposed to light at CT 16 , the $\mathrm{dKO}$ exhibited a significantly reduced magnitude of light-induced phase shifts. The light induction of c-Fos in the SCN is one of the most robust and wellcharacterized markers of photic regulation gene expression in the SCN (Kornhauser et al., 1990; Rieux et al., 2002). By this measure as well, the magnitude of the light induction was significantly reduced in $\mathrm{dKO}$ mice when compared with sKO or WT mice (Fig. 6). Finally, as described above, our physiological data demonstrate a reduction in the NMDA-evoked increase firing within the SCN of the mutant mice. Together, we feel that these data provide compelling evidence that the FDR current is essential for the ability of light to regulate the circadian system.

Our data also demonstrate that the output of the circadian system as measured by wheel-running behavior was dramatically compromised by the loss of the Kcnc genes. Under DD, the impact of light on the circadian system is minimal and the rhythms expressed are driven by the central clock and its output pathways. Under these conditions, the behavioral rhythms of all of the $\mathrm{dKO}$ mice were of low amplitude and lacked precision and coherence (Table 1). The power of the circadian oscillation as measured by periodogram as well as the overall levels of activity was significantly reduced in the $\mathrm{dKO}$ mice. The sKO mice did show a significant increase in the fragmentation of the activity cycle, so the loss of Kcnc2 did have some impact on the behavioral rhythm, but most of our behavioral observations of the sKO mice are consistent with previous work that failed to find an obvious behavioral phenotype associated with the loss of Kv3.2 alone (Lau et al., 2000; Vyazovskiy et al., 2002; Joho et al., 2006). The sKO did show a significant reduction in the FDR current in the SCN, but neither the firing rate nor the action potential width were significantly altered by the loss of just the Kv3.2 channel. The simplest explanation for our behavioral data is that the FDR current is essential for robust, coherent rhythms that are normally part of the circadian output. Behaviorally, the $\mathrm{dKO}$ mice show a circadian phenotype that shares a number of similarities to the vasoactive intestinal peptide (VIP)-deficient mice (Vosko et al., 2007), a finding that may give us a mechanistic handle on how VIP regulates the membrane properties of SCN neurons.

Our data do not provide clear evidence that the central clock was strongly impacted by the loss of the Kcnc genes. The circadian period length is the measurable parameter that is most indicative of the underlying circadian pacemaker system (Takahashi et al., 2008). In DD, the circadian period length (Tau) of the three genotypes was virtually identical (Table 1). Furthermore, the molecular clockwork as measured by the rhythm in PER2 protein expression was unaltered in the $\mathrm{dKO}$ (Fig. 5). Together, this experimental evidence raises the possibility that the molecular clockwork is operating normally in the absence of the FDR current. Previous work has suggested that the basic rhythms in clock gene expression that generate circadian oscillations are dependent on the generation of APs (Nitabach et al., 2002; Yamaguchi et al., 2003; Lundkvist et al., 2005). The dKO mice may provide an interesting case study to explore the relationship between electrical activity rhythms, which were disrupted, and clock gene expression, which appears to be intact in the mutant mice.

\section{References}

Baranauskas G (2007) Ionic channel function in action potential generation: current perspective. Mol Neurobiol 35:129-150.

Baranauskas G, Tkatch T, Nagata K, Yeh J, Surmeier DJ (2003) Kv3.4 subunits enhance the repolarizing efficiency of Kv3.1 channels in fast-spiking neurons. Nat Neurosci 6:258-266.

Berson DM, Dunn FA, Takao M (2002) Phototransduction by retinal ganglion cells that set the circadian clock. Science 295:1070-1073.

Block GD, Geusz M, Khalsa SB, Michel S, Whitmore D (1996) Circadian rhythm generation, expression and entrainment in a molluscan model system. Prog Brain Res 111:93-102.

Colwell CS (2000) Circadian modulation of calcium levels in cells in the suprachiasmatic nucleus. Eur J Neurosci 12:571-576.

Colwell CS (2001) NMDA-evoked calcium transients and currents in the suprachiasmatic nucleus: gating by the circadian system. Eur J Neurosci 13:1420-1428.

Colwell CS, Michel S, Itri J, Rodriguez W, Tam J, Lelievre V, Hu Z, Liu X, Waschek JA (2003) Disrupted circadian rhythms in VIP- and PHIdeficient mice. Am J Physiol Regul Integr Comp Physiol 285:R939-R949.

Colwell CS, Michel S, Itri J, Rodriguez W, Tam J, Lelièvre V, Hu Z, Liu X, Waschek JA (2004) Selective deficits in the circadian light response in mice lacking PACAP. Am J Physiol Regul Integr Comp Physiol 287:R1194-R1201.

Ding JM, Chen D, Weber ET, Faiman LE, Rea MA, Gillette MU (1994) Resetting the biological clock: mediation of nocturnal circadian shifts by glutamate and NO. Science 266:1713-1717.

Dragich JM, Loh DH, Wang LM, Vosko AM, Kudo T, Nakamura TJ, Odom IH, Tateyama S, Hagopian A, Waschek JA, Colwell CS (2010) The role of the neuropeptides PACAP and VIP in the photic regulation of gene expression in the suprachiasmatic nucleus. Eur J Neurosci 31:864-875.

Ho CS, Grange RW, Joho RH (1997) Pleiotropic effects of a disrupted K ${ }^{+}$ channel gene: reduced body weight, impaired motor skill and muscle contraction, but no seizures. Proc Natl Acad Sci U S A 94:1533-1538.

Irwin RP, Allen CN (2007) Calcium response to retinohypothalamic tract synaptic transmission in suprachiasmatic nucleus neurons. J Neurosci 27:11748-11757.

Itri JN, Michel S, Vansteensel MJ, Meijer JH, Colwell CS (2005) Fast delayed rectifier potassium current is required for circadian neural activity. Nat Neurosci 8:650-656.

Itri JN, Vosko AM, Schroeder A, Dragich JM, Michel S, Colwell CS (2010) Circadian regulation of A-type potassium currents in the suprachiasmatic nucleus. J Neurophysiol 103:632-640.

Joho RH, Hurlock EC (2009) The role of Kv3-type potassium channels in cerebellar physiology and behavior. Cerebellum 8:323-333.

Joho RH, Street C, Matsushita S, Knöpfel T (2006) Behavioral motor dysfunction in Kv3-type potassium channel-deficient mice. Genes Brain Behav 5:472-482.

Kim SM, Power A, Brown TM, Constance CM, Coon SL, Nishimura T, Hirai H, Cai T, Eisner C, Weaver DR, Piggins HD, Klein DC, Schnermann J, 
Notkins AL (2009) Deletion of the secretory vesicle proteins IA-2 and IA-2beta disrupts circadian rhythms of cardiovascular and physical activity. FASEB J 23:3226-3232.

Ko GY, Shi L, Ko ML (2009) Circadian regulation of ion channels and their functions. J Neurochem 110:1150-1169.

Kornhauser JM, Nelson DE, Mayo KE, Takahashi JS (1990) Photic and circadian regulation of $\mathrm{c}$-fos gene expression in the hamster suprachiasmatic nucleus. Neuron 5:127-134.

Kuhlman SJ, McMahon DG (2006) Encoding the ins and outs of circadian pacemaking. J Biol Rhythms 21:470-481.

Lau D, Vega-Saenz de Miera EC, Contreras D, Ozaita A, Harvey M, Chow A, Noebels JL, Paylor R, Morgan JI, Leonard CC, Rudy B (2000) Impaired fast-spiking, suppressed cortical inhibition, and increased susceptibility to seizures in mice lacking $\mathrm{Kv} 3.2 \mathrm{~K}^{+}$channel proteins. J Neurosci 20:9071-9085.

Lein E, Hawrylycz MJ, Ao N, Ayres M, Bensinger A, Bernard A, Boe AF, Boguski MS, Brockway KS, Byrnes EJ, Chen L, Chen L, Chen TM, Chin MC, Chong J, Crook BE, Czaplinska A, Dang CN, Datta S, Dee NR, et al. (2007) Genome-wide atlas of gene expression in the adult mouse brain. Nature 445:168-176.

Lundkvist G, Kwak Y, Davis E, Tei H, Block G (2005) A calcium flux is required for circadian rhythm generation in mammalian pacemaker neurons. J Neurosci 25:7682-7686.

Martina M, Schultz JH, Ehmke H, Monyer H, Jonas P (1998) Functional and molecular differences between voltage-gated $\mathrm{K}^{+}$channels of fastspiking interneurons and pyramidal neurons of rat hippocampus. J Neurosci 18:8111-8125.

Maywood E, O’Neill J, Reddy A, Chesham J, Prosser H, Kyriacou C, Godinho S, Nolan P, Hastings M (2007) Genetic and molecular analysis of the central and peripheral circadian clockwork of mice. Cold Spring Harb Symp Quant Biol 72:85-94.

Meijer JH, Watanabe K, Schaap J, Albus H, Détári L (1998) Light responsiveness of the suprachiasmatic nucleus: long-term multiunit and singleunit recordings in freely moving rats. J Neurosci 18:9078-9087.

Michel S, Itri J, Han JH, Gniotczynski K, Colwell CS (2006) Regulation of glutamatergic signalling by PACAP in the mammalian suprachiasmatic nucleus. BMC Neurosci 7:15.

Nitabach MN, Blau J, Holmes TC (2002) Electrical silencing of Drosophila pacemaker neurons stops the free-running circadian clock. Cell 109: 485-495.

Ozaita A, Petit-Jacques J, Völgyi B, Ho CS, Joho RH, Bloomfield SA, Rudy B (2004) A unique role for Kv3 voltage-gated potassium channels in starburst amacrine cell signaling in mouse retina. J Neurosci 24:7335-7343.

Panda S, Antoch MP, Miller BH, Su AI, Schook AB, Straume M, Schultz PG, Kay SA, Takahashi JS, Hogenesch JB (2002) Coordinated transcription of key pathways in the mouse by the circadian clock. Cell 109:307-320.

Rieux C, Carney R, Lupi D, Dkhissi-Benyahya O, Jansen K, Chounlamountri N, Foster RG, Cooper HM (2002) Analysis of immunohistochemical label of Fos protein in the suprachiasmatic nucleus: comparison of different methods of quantification. J Biol Rhythms 17:121-136.
Rudy B, McBain CJ (2001) Kv3 channels: voltage-gated $\mathrm{K}^{+}$channels designed for high-frequency repetitive firing. Trends Neurosci 24:517-526.

Rudy B, Chow A, Lau D, Amarillo Y, Ozaita A, Saganich M, Moreno H, Nadal MS, Hernandez-Pineda R, Hernandez-Cruz A, Erisir A, Leonard C, VegaSaenz de Miera E (1999) Contributions of Kv3 channels to neuronal excitability. Ann N Y Acad Sci 868:304-343.

Schaap J, Pennartz CM, Meijer JH (2003) Electrophysiology of the circadian pacemaker in mammals. Chronobiol Int 20:171-188.

Schwartz WJ, Gross RA, Morton MT (1987) The suprachiasmatic nuclei contain a tetrodotoxin-resistant circadian pacemaker. Proc Natl Acad Sci U S A 84:1694-1698.

Shearman LP, Zylka MJ, Weaver DR, Kolakowski LF Jr, Reppert SM (1997) Two period homologs: circadian expression and photic regulation in the suprachiasmatic nuclei. Neuron 19:1261-1269.

Sheeba V, Gu H, Sharma VK, O'Dowd DK, Holmes TC (2008) Circadianand light-dependent regulation of resting membrane potential and spontaneous action potential firing of Drosophila circadian pacemaker neurons. J Neurophysiol 99:976-988.

Takahashi JS, Hong HK, Ko CH, McDearmon EL (2008) The genetics of mammalian circadian order and disorder: implications for physiology and disease. Nat Rev Genet 9:764-775.

Tu DC, Zhang D, Demas J, Slutsky EB, Provencio I, Holy TE, Van Gelder RN (2005) Physiologic diversity and development of intrinsically photosensitive retinal ganglion cells. Neuron 48:987-999.

Vosko AM, Schroeder A, Loh DH, Colwell CS (2007) Vasoactive intestinal peptide and the mammalian circadian system. Gen Comp Endocrinol 152:165-175.

Vyazovskiy VV, Deboer T, Rudy B, Lau D, Borbély AA, Tobler I (2002) Sleep EEG in mice that are deficient in the potassium channel subunit Kv3.2. Brain Res 947:204-211.

Wang LY, Gan L, Forsythe ID, Kaczmarek LK (1998) Contribution of the Kv3.1 potassium channel to high-frequency firing in mouse auditory neurones. J Physiol 509:183-194.

Wang L, Dragich J, Kudo T, Odom I, Welsh D, O’Dell T, Colwell C (2009) Expression of the circadian clock gene Period2 in the hippocampus: possible implications for synaptic plasticity and learned behaviour. ASN Neuro pii:e00012.

Warren EJ, Allen CN, Brown RL, Robinson DW (2003) Intrinsic light responses of retinal ganglion cells projecting to the circadian system. Eur J Neurosci 17:1727-1735.

Weiser M, Vega-Saenz de Miera E, Kentros C, Moreno H, Franzen L, Hillman D, Baker H, Rudy B (1994) Differential expression of Shaw-related $\mathrm{K}^{+}$ channels in the rat central nervous system. J Neurosci 14:949-972.

Welsh DK, Takahashi JS, Kay SA (2010) Suprachiasmatic nucleus: cell autonomy and network properties. Annu Rev Physiol 72:551-577.

Yamaguchi S, Isejima H, Matsuo T, Okura R, Yagita K, Kobayashi M, Okamura H (2003) Synchronization of cellular clocks in the suprachiasmatic nucleus. Science 302:1408-1412. 